\section{Commentary: Don't forget to re-SAVR the moment}

\author{
Ryan Plichta, MD, and Edward P. Chen, MD
}

Redo surgical aortic valve replacement (re-SAVR) has been the traditional standard treatment for addressing a failed bioprosthetic aortic valve. Since its initial description in 2007, the emergence of valve-in-valve transcatheter aortic valve replacement (VIV TAVR) has become an attractive option for patients and physicians owing to the reduced burden of operative insult and procedural recovery compared with a repeat sternotomy.

In this issue of the Journal, Greason ${ }^{1}$ provides a thoughtful and compelling argument for the safety, effectiveness, and hence consideration of re-SAVR when faced with biological aortic valve prosthesis failure. Most importantly, re-SAVR can be performed with a low operative mortality. In several referenced reports, re-SAVR carries similar operative mortality as primary aortic valve replacement. However, in the Society of Thoracic Surgeons Adult Cardiac Database study, Kaneko and colleagues ${ }^{2}$ reported a significant increase in operative mortality with re-SAVR compared with primary SAVR $(5.4 \%$ vs $2.7 \% ; P<.001)$. Possible explanations for this discrepancy include lack of operator skill, insufficient study power to demonstrate a statistical difference, as well as a higher patient risk profile.

Comparative data for re-SAVR versus VIV TAVR demonstrate similar operative mortality in centers of expertise. Although administrative database studies report higher 30-day mortality with re-SAVR, there are certainly gaps in important echocardiography data and lack of real-world representation. Despite the initial survival advantage of VIV TAVR, longer-term follow-up has shown that the

\footnotetext{
From the Division of Cardiovascular and Thoracic Surgery, Department of Surgery, Duke University Medical Center, Durham, NC.

Disclosures: The authors reported no conflicts of interest.

The Journal policy requires editors and reviewers to disclose conflicts of interest and to decline handling or reviewing manuscripts for which they may have a conflict of interest. The editors and reviewers of this article have no conflicts of interest.

Received for publication Jan 28, 2021; revisions received Jan 28, 2021; accepted for publication Jan 28, 2021; available ahead of print Feb 4, 2021.

Address for reprints: Edward P. Chen, MD, DUMC 3442, Duke University Medical Center, Durham, NC, 27710 (E-mail: edward.p.chen@duke.edu).

J Thorac Cardiovasc Surg 2022;163:944-5

$0022-5223 / \$ 36.00$

Copyright (c) 2021 by The American Association for Thoracic Surgery

https://doi.org/10.1016/j.jtcvs.2021.01.122
}

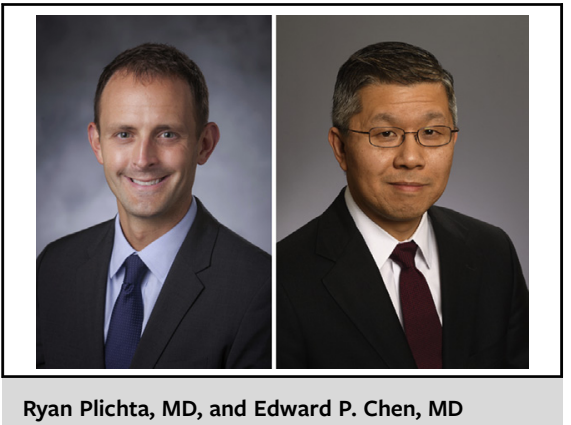

CENTRAL MESSAGE

Redo-surgical aortic valve

replacement is a safe and effec-

tive strategy for management of

a failed bioprosthetic aortic

valve. A patient-centered

approach that considers the risks

and benefits is key.

survival curves cross at 2 years, demonstrating a survival benefit for re-SAVR. ${ }^{3}$

Despite the increased operative burden placed on the patient, re-SAVR has several advantages over VIV TAVR, including complete removal of the previously placed prosthesis, the ability to address concomitant cardiac issues, the ability to address a small annulus with an enlargement procedure, as well as the option to implant a mechanical prosthesis.

Perhaps the single most compelling advantage of re-SAVR lies in the reduced incidence of prosthesispatient mismatch (PPM) with re-SAVR compared with VIV TAVR. With growing evidence of the negative impact of PPM on outcomes, minimizing its occurrence following any type of aortic valve intervention will be absolutely critical to long-term patient survival. It is concerning that the incidence of PPM following VIV TAVR was not only quite common $(44 \%)$, but even worse for those patients who received a $23-\mathrm{mm}$ or smaller VIV TAVR $(66 \%)$. These rates are much higher compared with those in the re-SAVR groups $(12 \%$ and $17 \%){ }^{3}$

We acknowledge that re-SAVR and VIV TAVR should be viewed as complementary therapies and not competitive. Greason should be commended for his emphasis on the need for an optimal operation at the initial aortic valve replacement procedure. There are certainly patients who will be better served with a VIV TAVR approach, just as 
there will be patients for whom re-SAVR is most appropriate.

Perhaps the author's most important message lies in the emphasis on the need for "patient centeredness." Focusing on patient-oriented benefits and providing them with complete transparency of outcomes as well as procedurespecific risks and benefits is absolutely critical.

\section{References}

1. Greason KL. Repeat surgical aortic valve replacement: don't stick a fork in it jus yet. J Thorac Cardiovasc Surg. 2022;163:940-3.

2. Kaneko T, Vassileva CM, Englum B, Kim S, Yammine M, Brennan M, et al Contemporary outcomes of repeat aortic valve replacement: a benchmark for transcatheter valve-in-valve procedures. Ann Thorac Surg. 2015;100:1298-304.

3. Sedeek AF, Greason KL, Sandhu GS, Dearani JA, Holmes DR, Schaff HV. Trans catheter valve-in-valve vs surgical replacement of failing stented aortic biological valves. Ann Thorac Surg. 2019;108:424-30.
See Article page 940.

\section{Commentary: Reintervention for a failed surgical aortic bioprosthesis: Procedure- or patient-driven strategy?}

\author{
Siamak Mohammadi, MD, FRCSC, and \\ Dimitri Kalavrouziotis, MD, FRCSC
}

Aortic bioprosthetic valve failure due to structural valve degeneration generally requires a reintervention either by redo surgical aortic valve replacement (re-SAVR), or a valve-in-valve transcatheter aortic valve replacement (ViV-TAVR), based on a patient's risk stratification. The availability of ViV-TAVR has provided the impetus for more liberal use of bioprostheses in younger patients. ${ }^{1,2}$ However, the safety and efficacy of ViV-TAVR have been investigated by observational studies that exclusively included patients with a high or prohibitive risk of reSAVR. ${ }^{3,4}$ Therefore, specific indications and the relative merits of re-SAVR versus ViV-TAVR in wider populations of patients with deteriorated aortic bioprostheses remains unknown, especially considering the importance of longterm outcomes in patients with a higher life expectancy.

\footnotetext{
From the Department of Cardiac Surgery, Québec Heart and Lung Institute, Québec City, Québec, Canada.

Disclosures: The authors reported no conflicts of interest.

The Journal policy requires editors and reviewers to disclose conflicts of interest and to decline handling or reviewing manuscripts for which they may have a conflict of interest. The editors and reviewers of this article have no conflicts of interest

Received for publication Feb 10, 2021; revisions received Feb 10, 2021; accepted for publication Feb 11, 2021; available ahead of print Feb 17, 2021

Address for reprints: Siamak Mohammadi, MD, FRCSC, Department of Cardiac Surgery, Quebéc Heart and Lung Institute, 2725 chemin Sainte-Foy, Québec City, Québec G1V 4G5 Canada (E-mail: siamak.mohammadi@fmed.ulaval.ca).

J Thorac Cardiovasc Surg 2022;163:945-6

$0022-5223 / \$ 36.00$

Copyright (C) 2021 by The American Association for Thoracic Surgery

https://doi.org/10.1016/j.jtcvs.2021.02.032
}

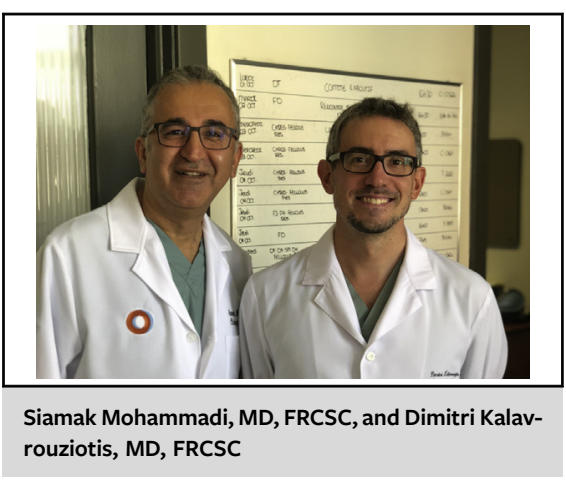

CENTRAL MESSAGE

There is a definite role for redo surgical aortic valve replacement in contemporary practice, especially in younger patients for whom the avoidance of prosthesis-patient mismatch is paramount.

Greason $^{5}$ wrote a thoughtful expert opinion article in which he asks: Is there a role for re-SAVR in contemporary practice? The immediate benefits of ViV-TAVR, including the avoidance of thoracic re-entry and its associated morbidity are certainly attractive. But, the author suggests, it may be worth risking a trip through the potential minefield of re-SAVR to reap long-term benefits on the other side. These benefits are largely 2-fold: the ability to address concomitant cardiac pathology, and the avoidance of prosthesis-patient mismatch (PPM), both of which are more effectively addressed (in general) during re-SAVR. The minefield of re-SAVR is a hypothesis that has not materialized in most studies because similar operative mortality between re-SAVR and ViV-TAVR can be achieved in 